\title{
Evaluating Optimal Parameters for Machining Selective Laser Melting Titanium Alloy Using Wire Cut Electrical Discharge Machining
}

Ashwin Polishetty, AUT Univesity, Auckland, New Zealand

Guy Littlefair, AUT Univesity, Auckland, New Zealand

\begin{abstract}
Titanium is known for its poor machinability characteristics due to its low thermal conductivity and high chemical reactivity. This article explores the machinability characteristics of selective laser melting (SLM) titanium alloy Ti-6Al-4V using wire cut electrical discharge machining (WEDM). For titanium alloys, exploring non-traditional machining operation such as WEDM is critical for a material failure or success in a design application. The research is to study the effect of parameters such as servo voltage, pulse on/off, and machining speed with respect to wire tension and wire feed rate on machinability. The outputs under consideration for evaluating machinability are metal removal rate (MRR) and surface finish under minimal interruption due to wire snaps. The article concludes by identifying the optimal factors responsible to produce an efficient and accurate cut with a minimum downtime.
\end{abstract}

\section{KEYWORDS}

Machinability, Selective Laser Melting, Titanium Alloys, Wire Cut Electrical Discharge Machining

\section{INTRODUCTION}

Titanium alloys are reputed for their material properties such as high specific strength, biocompatibility and corrosion resistance. Despite their superior properties, their extraction, fabrication and production are expensive due to the requirement of a protective environment, high energy consumption and various other manufacturing associated problems (Boyer, 2010). Titanium alloy, Ti-6Al-4V, having superior mechanical properties, is often referred to as the work horse of titanium alloys and is preferentially used in a variety of applications in the aerospace, chemical, biomedical and automotive industries (Shunmugavel, Polishetty, \& Littlefair, 2017). To decrease the overall cost of production and to improve productivity, research on alternative manufacturing methods of titanium alloy has been the primary point of focus (Lutjering \& Williams, 2007). In recent years, additive manufacturing (AM) has been widely used for fabricating near-net shape titanium alloy (Ti-6Al-4V) products due to its advantageous features like freedom of design, on-demand manufacturing and high productivity. 
Titanium alloys are used to manufacture components, where the requirements of design reliability and superior material properties such as high corrosion and thermal resistance, high robustness, high strength to weight ratio and outstanding tendency of alloying, is a priority (Koster, Field, Kahles, Fritz, $\&$ Gatto, 1970). The higher melting point of titanium alloy makes it a superior alloy in comparison to other metals. However, some of the material properties of titanium such as low thermal conductivity and high chemical reactivity leads to poor machinability characteristics (Che-Haron, 2001; Polishetty, Shunmugavel, Goldberg, Littlefair, \& Singh, 2017). The material used for this project is a SLM titanium alloy, Ti-6Al-4V. SLM is suitable for rapid generation of metal 3D print prototypes. The material properties of SLM titanium alloy, Ti-6Al-4V are given in Table 1.

Table 1. Material properties of SLM titanium alloy, Ti-6AI-4V

\begin{tabular}{|c|l|l|l|l|}
\hline \multicolumn{1}{|c|}{ Material } & \multicolumn{1}{|c|}{ Density, lbs./inch ${ }^{3}$} & $\begin{array}{c}\text { Ultimate Tensile } \\
\text { Strength (UTS), } \\
\text { MPa }\end{array}$ & Yield strength, MPa & $\begin{array}{c}\text { Youngs Modulus, } \\
\text { GPa }\end{array}$ \\
\hline SLM Ti-6Al-4V & 0.16 & 950 & 880 & 114 \\
\hline
\end{tabular}

\section{Selective Laser Melting (SLM)}

The development of Additive Manufacturing (AM) technology has made it possible to lower the production cost and the energy consumption as well as the carbon footprint compared to a conventional manufacturing process. The chemical composition of Ti-6Al-4V is given in Table 2 . The characteristics of AM ensures feasibility for dental and orthopedic implants in the biomedical

Table 2. Chemical composition of SLM Titanium alloy, Ti-6Al-4V

\begin{tabular}{|c|c|c|c|c|c|c|c|c|}
\hline & Al & $\mathbf{V}$ & $\mathbf{F e}$ & $\mathbf{C}$ & $\mathbf{O}$ & $\mathbf{N}$ & $\mathbf{H}$ & $\mathbf{T i}$ \\
\hline SLM Ti-6Al-4V & $6.82 \%$ & $4.20 \%$ & $0.325 \%$ & $0.025 \%$ & $0.20 \%$ & $0.041 \%$ & $0.0047 \%$ & Bal. \\
\hline
\end{tabular}

industry provided, the required finish and form is achieved (Ahn et al., 2017). Considered to be the future of manufacturing, AM printers and the materials have evolved rapidly in the last decade. Huang et al. points out the benefits of AM over the traditional methods with respect to production flexibility, material efficiency and direct kitting (Huang, Liu, Mokasdar, \& Hou, 2013). These advantages enable AM to be a good replacement for conventional manufacture of complex structures (Mellor, Hao, \& Zhang, 2014). AM has moved from prototyping applications to the actual parts production with the rapid advancement of material and manufacturing technologies. AM has created freedom in design of a product compared to the existing manufacturing techniques. This shift has created a new space for AM in the industries such as aerospace, healthcare and automotive. With the advancement of AM technology, SLM developed in 1995, has turned out to be a prominent metallic 3D printing process because of its better accuracy and efficiency (Li, Kucukkoc, \& Zhang, 2017). A SLM metal printer manufactured, supplied, and technology patented by SLM solutions and used in this research is shown in Figure 1. Selective Laser Melting (SLM), is a type of AM technique, which involves layer by layer manufacturing using a micrometer sized particle powder and laser beam as source of heat to melt and bind the powder (Polishetty et al., 2017; Shunmugavel, Polishetty, \& Littlefair, 2015). In order to avoid oxidation of the metal powder, it is recommended that the SLM process takes place in an inert atmosphere. To achieve this, a vacuum chamber with a nitrogen or argon atmosphere 


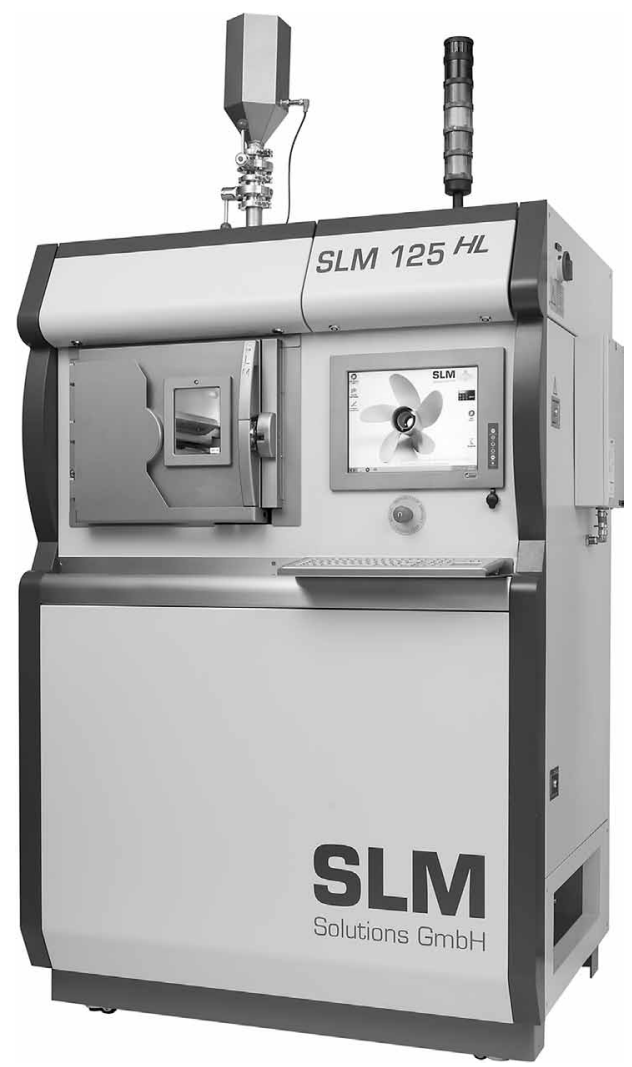

with minimal amount of oxygen is maintained. An initial layer of powder is distributed over an electronically controlled platform and is melted with the help of laser by scanning through the layer. To begin with, a complete 3D model of the specimen is made using CAD software. The model is then divided into various layers of micrometer thickness with the help of a customized AM software (Polishetty et al., 2017). A fresh layer is spread over the melted powder and fuse with the previous layer. The process repeats till the entire component is finished as per the CAD data. In SLM, the laser performs an essential operation of scanning of the thin layer of the powder which are deposited on the base of the chamber. The process of material forming goes in the same direction of laser beam scanning. Sequentially, elongated lines of molten powder are filled in every cross-section of the part. The quality of the specimen manufactured by SLM method will depend on the layer thickness, powder size, power of the laser beam, scanning speed, hutching, the orientation and build-direction (Shunmugavel et al., 2015). Hence, SLM manufacturing process is parameter sensitive process. SLM manufactured specimens show high tensile, compression, hardness, and part density as compared to wrought materials, this is because the parts are subjected to high cooling rates during manufacturing process which results in a short grain microstructure. Though, they are reported with low fatigue strengths, caused by the defects during production like porosity, inclusions and anisotropy (Shamsaei, Yadollahi, Bian, \& Thompson, 2015).

Currently, there are more than ten materials compatible for this fabrication method which includes high quality steel, nickel-based alloys, aluminium and titanium. The powder grain size of these materials ranges from $10 \mu \mathrm{m}$ to $60 \mu \mathrm{m}$ and the accuracy of part produced will be at a tolerance of $\pm 50 \mu \mathrm{m}$ (Bartolomeu et al., 2017). 


\section{Wire Cut Electrical Discharge Machining (WEDM)}

The phenomenon of Electrical Discharge Machining (EDM) was initially observed by a physicist, Joseph Preistly in 1770. During an experiment, due to electric discharges there was some material removed from the electrode. Later, further research on the observed phenomena had led to the development of the EDM process (Krar, 2003). EDM is a machining process in which a desired shape is obtained by path guided wire cuts using a series of electric discharges. In this process, the two electrodes-anode and cathode are submerged into the dielectric fluid, which would act as the control medium. One of the electrodes would be the tool which carries the high voltage and second electrode would be the material itself which would be receiving the high voltage. In this process, there would be no real contact between tool and the material for metal removal. Instead, the tool is placed very closed to the material at microns distance and this helps in generating a strong electric field or plasma region in the gap (Ho \& Newman, 2003). The high voltage carried in the tool would create an electric spark on the material or workpiece surface generating temperature around 8000$12000^{\circ} \mathrm{C}$ which is high enough to melt most metals. The dielectric fluid helps in control of spark generation and indirectly helps in precisely removing of the required material. Also, the removed molten material would be flushed away from the workpiece through the dielectric fluid leading to superior surface finish without leaving any burr. Modern day design requirements with more emphasis on high productivity and better quality especially in biomedical and aerospace industry has led to technology enhancement with a minimum downtime. There are various ways to achieve or use the technology such as EDM, WEDM, Strip Electric Discharge Machining (SEDM), Dry Electric Discharge Machine (DEDM) and 5- Axis Electric Discharge Machine (5-axis EDM) (Suryakant \& Allurkar, 2016). WEDM has been used in this research work.

In WEDM, a metallic wire is used instead of a basic tool/sacrificial metallic electrode as used in EDM. This process is mostly used for creating the blanking punches and the extrusion dies from a hard material which are difficult to machine. With the help of a CNC controller, very accurate cuts can be made on the material. WEDM would also provide ability to achieve tapered cut and transitioning shapes or any intricate shapes. Skim cuts for removing excess material post machining is also possible using WEDM. For skim cuts, the wire is made to pass backward and forward over a rough surface with relatively low voltage for removing the excess material. WEDM involves conductive wire running in a closed loop and traversing along a defined path cuts the workpiece to generate the required shape and profile. The workpiece acts as an electrode for this process. This cutting process helps in achieving very accurate 2D profile cutting of the material (Krar \& Gill, 2003). Few parameters which effect the WEDM process are wire diameter, discharge current, voltage rating, wire tension, wire material, workpiece material, pulse width, pulse duration, pressure of dielectric injection and polarity (Patel \& Achwal, 2013). The common areas of applying WEDM are medical, aerospace and semi-conductor industry; industrial die and tool industry; hard extruded die cutting; gears, punch or die cutting and micro manufacturing such as micro tools or micro machining process (Krar \& Gill, 2003).

\section{LITERATURE REVIEW}

There are various research works carried out on the SLM process especially titanium alloys, mostly on alloy Ti-6Al-4V. The results show that the SLM processed specimens of Ti-6Al-4V alloy can achieve high specific strengths, even in case of repeated loading and crack growth. However, for optimizing properties like ductility, hardness, etc. specific treatments were necessary after the SLM production process. This was due to the defects such as porosity caused during the production process. Majumder et.al studied the effect of machining parameters on the material removal rate and electrode wear during EDM of mild steel. The input parameters-supply current, pulse on time and pulse off time where compared against output parameters Metal Removal Rate (MRR) and electrode wear (Majumder, 2012). Anish et.al carried out research on predicting the surface roughness in a WEDM process 
based on response surface methodology. The material used in this research was commercially pure titanium. The effect of parameters such as pulse on, pulse off time, peak current, spark gap voltage, wire feed and wire tension on surface roughness was evaluated (Kumar, Kumar, \& Kumar, 2012). Harpreet et.al. studied the effect of pulse on/off on machining of steel using cryogenic treated copper electrode. The material used in this research was steel (Singh \& Singh, 2013). S.V. Subrahmanyam et.al. evaluated the optimal parameters for machining with WEDM using grey-taguchi method. The material used in this research was a hot die tool steel. The effect of input parameters such as discharge current, pulse on/off time, spark voltage, wire feed, wire tension, servo feed and flushing pressure was evaluated using output parameters MRR and surface roughness (Subrahmanyam \& Sarcar, 2013).

\section{EXPERIMENTAL DESIGN}

The aim of this project is to study the optimal parameters that affect the cutting process of SLM Titanium alloy, Ti-6Al-4V using WEDM in different machining conditions. The cut thickness was approximately $5.25 \mathrm{~mm}$ and cut length was $16.25 \mathrm{~mm}$. The WEDM process was done using Makino U3 wire electro discharge machine as shown in Figure 2. Zinc coated brass round wire of diameter;

\section{Figure 2. Makino Wire Electro Discharge machine}

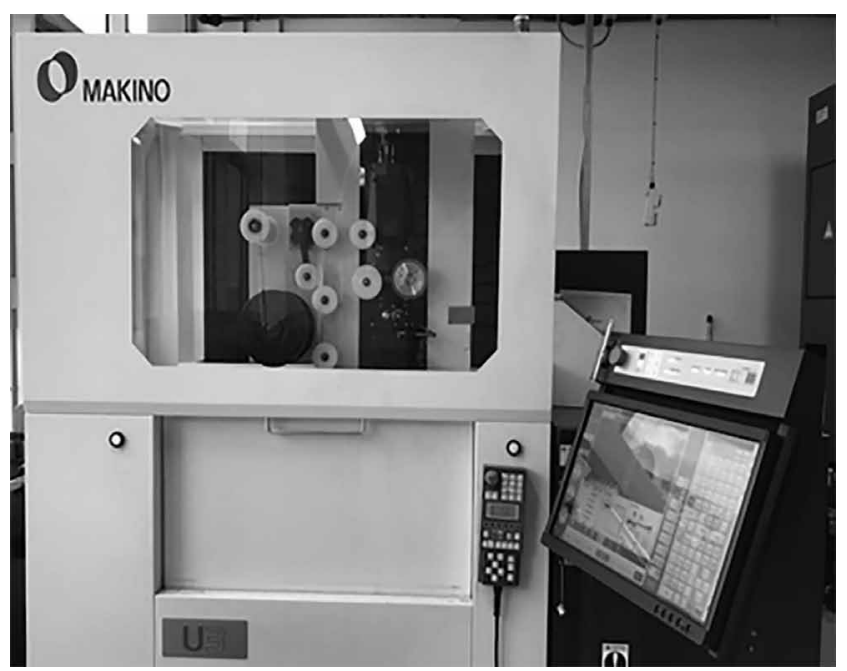

0.012 inch was used. The dielectric used during the process was de-ionised water. The wire tension remains constant for all the trials. The trials were repeated four times for each cut condition depending upon the material availability and size. Hence, there were a total of 12 samples to be analysed at the end of the machining trials. The cut samples were subjected to surface roughness analysis using an optical profilometry technique. Alicona 3D optical profilometer was used for to generate 3D surface profiles. The metal removal rate (MRR) was also calculated for each cut. Mean value of the four instances was considered for results and analysis. The experimental design consists of conducting the trials using the WEDM under three cut conditions viz. C1-speed; C2-precision and C3- single pass. The cutting parameters for conditions $\mathrm{C} 1, \mathrm{C} 2$ and $\mathrm{C} 3$ are defined in Table 3. The sample used for the machining trials is a SLM titanium alloy Ti-6Al-4V of approximate dimension width $-5 \mathrm{~mm}$ and $16 \mathrm{~mm}$ wide which also represents the cut area as shown in Figure 3. 
Table 3. Cutting parameters for conditions, C1-Speed, C2-Precision and C3- Single pass

\begin{tabular}{|l|l|l|l|}
\hline \multicolumn{1}{|c|}{ Parameters } & \multicolumn{1}{c|}{ Speed } & \multicolumn{1}{c|}{ Precision } & \multicolumn{1}{c|}{ Single pass } \\
\hline Pulse on A $(\mu \mathrm{s})$ & 38 & 37 & 3 \\
\hline Pulse on B $(\mu \mathrm{s})$ & 45 & 44 & 3 \\
\hline Pulse off $(\mu \mathrm{s})$ & 105 & 112 & 35 \\
\hline Current $($ Amp) & 19 & 18 & 28 \\
\hline Wire Tension $(\mathrm{N})$ & 9 & 9 & 9 \\
\hline Wire Feed rate $(\mathrm{mm} / \mathrm{s})$ & 18 & 16 & 16 \\
\hline $\begin{array}{l}\text { Spark gap width/ Servo } \\
\text { voltage }(v)\end{array}$ & 138 & 140 & 65 \\
\hline
\end{tabular}

Figure 3. SLM titanium alloy, Ti-6Al-4V sample

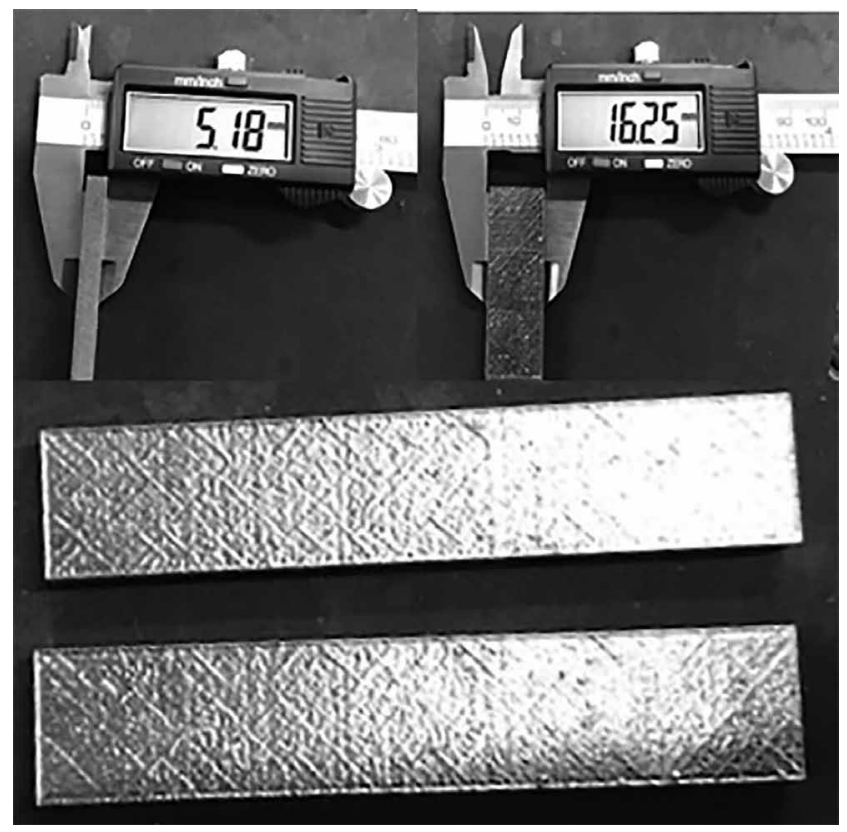

\section{RESULTS AND DISCUSSION}

The data obtained from the experiments are analysed and discussed in this section. The outputs under consideration are the Metal Removal Rate (MRR) and surface roughness ( $\mathrm{Ra}$ ). The variation of the MRR with respect to the pulse on and servo voltage for the three conditions $\mathrm{C} 1, \mathrm{C} 2$ and $\mathrm{C} 3$ is shown in Figure 4 and Figure 5 respectively.

From Figure 4, MRR was comparatively low for a single pass condition (C3). The probable reason can be the increase in machining time to ensure a cut without the wire snap. Wire snap is the worst outcome to expect in a WEDM as it can drastically reduce the productivity due to the machine downtime. There was no big difference in the MRR for a speed $(\mathrm{C} 1)$ and precision $(\mathrm{C} 2)$ cut indicating that a balance can be achieved between the speed and precision depending on the design requirements. A comparison of the MRR with the parameter, servo voltage (V) was also done. Servo voltage is the work potential required to perform the necessary cut. As observed in Figure 5, MRR is 
Figure 4. MRR variation with respect to the pulse on for cut conditions $\mathrm{C} 1, \mathrm{C} 2$ and $\mathrm{C3}$

\section{Mean MRR}

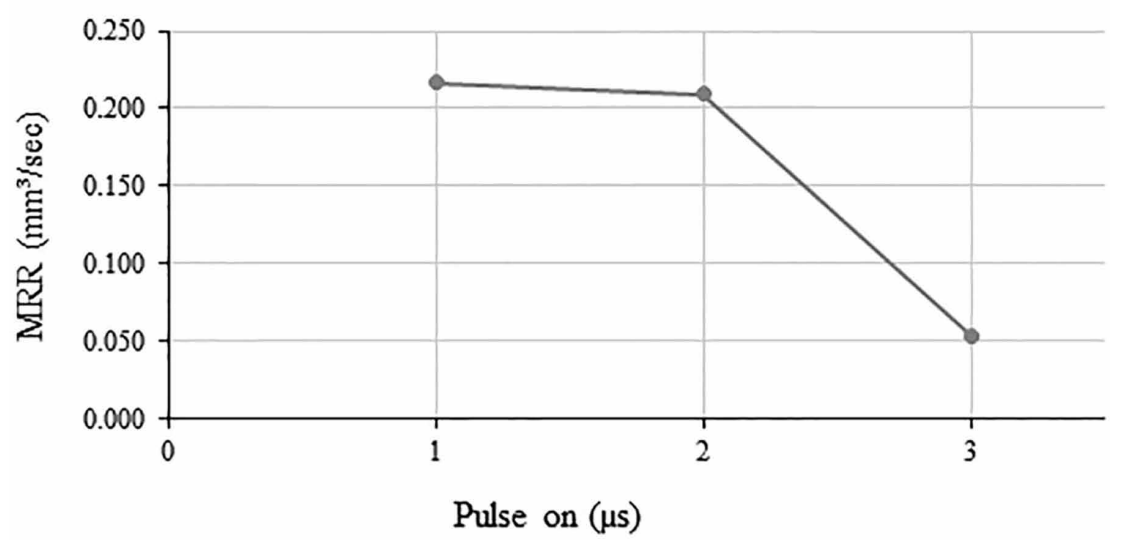

Figure 5. MRR variation with respect to servo voltage for cut conditions $\mathrm{C} 1, \mathrm{C} 2$ and $\mathrm{C} 3$

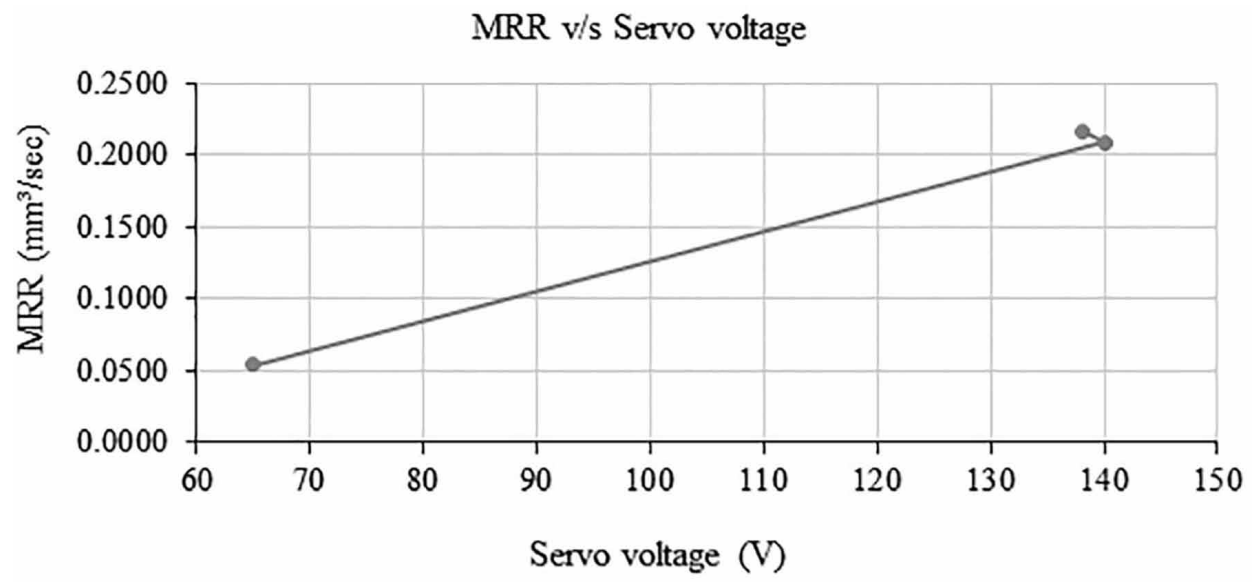

directly proportional to the servo voltage. An alignment in the results can be observed for a single pass condition (C3) as it has a lower voltage to ensure a successful cut and hence, a lower MRR. The MRR variations with respect to the surface roughness is shown in Figure 6. From Figure 6, for a single pass condition (C3) having low MRR, a better surface finish or low surface roughness (Ra) is obtained.

An in-depth analysis of the surface roughness variations with respect to the machining speed for the cut conditions C1, C2 and C3 is shown in Figure 7. An analogy similar to the graph in Figure 6 can be harmonised to the observations in figure 7 as machining speed is directly proportional to the MRR. Mostly for any cut conditions, C1, C2 and C3, as the machining speed increases, the surface roughness $(\mathrm{Ra})$ increases.

\section{CONCLUSION}

The following conclusion can be drawn from this research on parameter optimisation of the WEDM process especially for an additive manufactured material such as titanium alloy, Ti-6Al-4V. 
Figure 6. MRR variation with respect to surface roughness for cut conditions $\mathrm{C1}, \mathrm{C2}$ and $\mathrm{C3}$

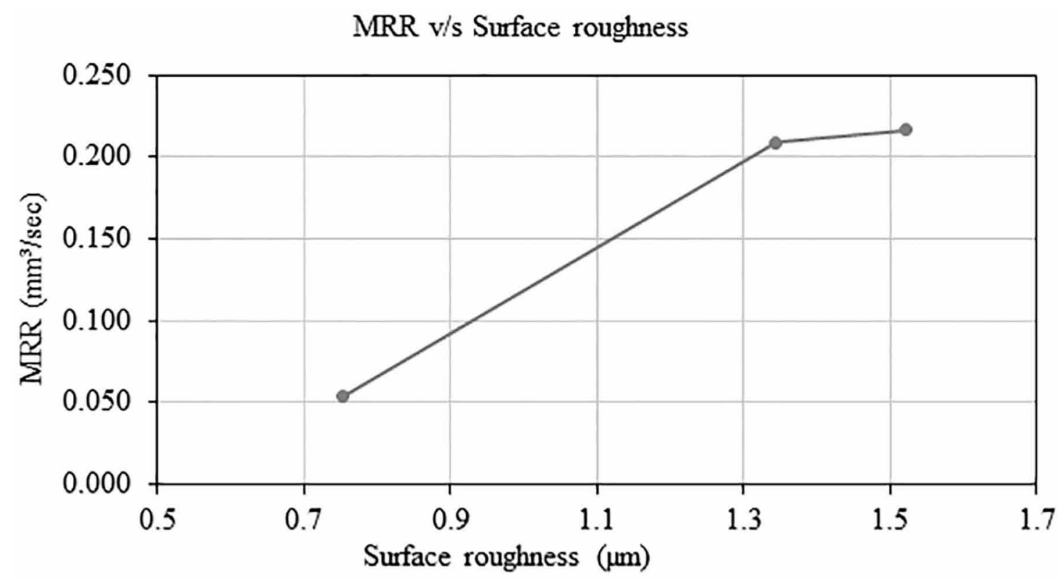

Figure 7. Surface roughness $(\mathrm{Ra})$ variation with respect to the machining speed for cut conditions $\mathrm{C} 1, \mathrm{C} 2$ and $\mathrm{C} 3$

Surface roughness v/s Machining speed for condition C1

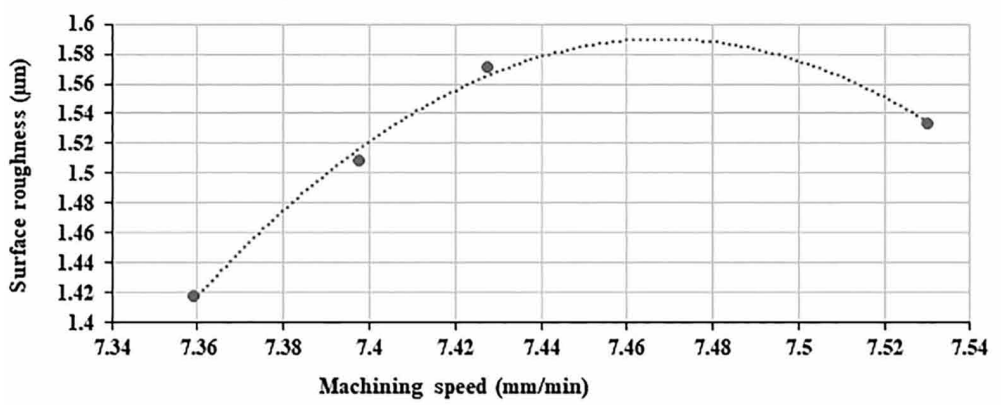

Surface roughness $\mathrm{v} / \mathrm{s}$ Machining speed for condition C2

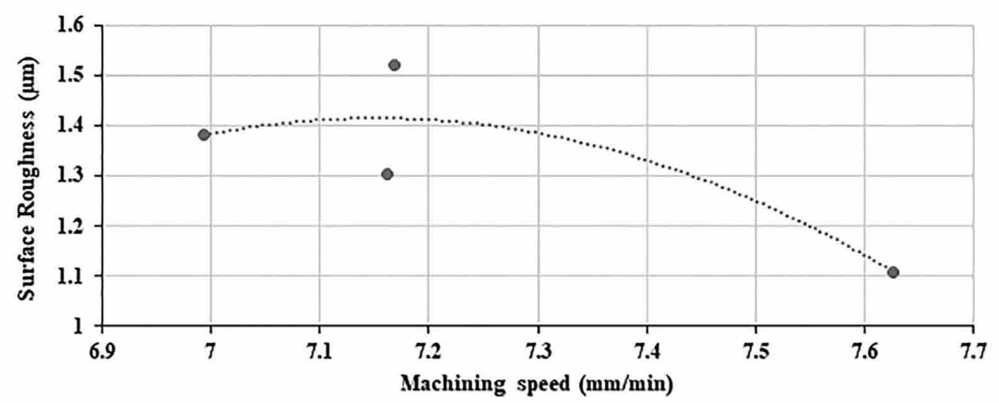

Suraface roughness v/s Machining speed for condition C3

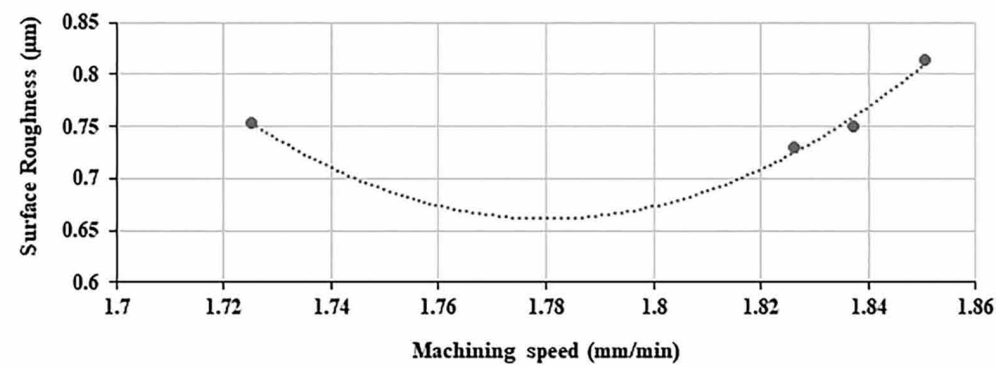


- The MRR for a single pass condition (C3) was very low compared to the other cut conditions, $\mathrm{C} 2$ and $\mathrm{C} 3$ but the productivity was optimum as a successful cut was generated without the wire snap/machine breakdown.

- There was no significant difference in MRR for a speed (C1) and precision (C2) cut indicating that a balance can be achieved between the speed and precision depending on the design requirements.

- The input parameters such as servo voltage influence the machining criteria and alter the design requirements.

- Surface roughness is influenced by MRR. A better surface finish or low surface roughness (Ra) can be obtained for a single pass condition (C3).

Future work to study the effect of varying thickness of the workpiece on cutting performance during a WEDM process can be undertaken. 


\section{REFERENCES}

Ahn, Y.-K., Kim, H.-G., Park, H.-K., Kim, G.-H., Jung, K.-H., Lee, C.-W., \& Lee, B.-S. et al. (2017). Mechanical and microstructural characteristics of commercial purity titanium implants fabricated by electron-beam additive manufacturing. Materials Letters, 187, 64-67. doi:10.1016/j.matlet.2016.10.064

Bartolomeu, F., Buciumeanu, M., Pinto, E., Alves, N., Carvalho, O., Silva, F. S., \& Miranda, G. (2017). 316L stainless steel mechanical and tribological behavior-A comparison between selective laser melting, hot pressing and conventional casting. Additive Manufacturing, 16, 81-89. 10.1016/j.addma.2017.05.007

Boyer, R. (2010). Attributes, characteristics, and applications of titanium and its alloys. JOM, 62(5), 21-24. doi:10.1007/s11837-010-0071-1

Çaydaş, U., \& Ekici, S. (2012). Support vector machines models for surface roughness prediction in CNC turning of AISI 304 austenitic stainless steel. Journal of Intelligent Manufacturing, 23(3), 639-650. doi:10.1007/ s10845-010-0415-2

Che-Haron, C. (2001). Tool life and surface integrity in turning titanium alloy. Journal of Materials Processing Technology, 118(1-3), 231-237. doi:10.1016/S0924-0136(01)00926-8

Ho, K. H., \& Newman, S. T. (2003). State of the art electrical discharge machining (EDM). International Journal of Machine Tools \& Manufacture, 13(13), 1287-1300. doi:10.1016/S0890-6955(03)00162-7

Huang, S. H., Liu, P., Mokasdar, A., \& Hou, L. (2013). Additive manufacturing and its societal impact: A literature review. International Journal of Advanced Manufacturing Technology, 67(5), 1191-1203. doi:10.1007/ s00170-012-4558-5

Koster, W. P., Field, M., Kahles, J. F., Fritz, L. J., \& Gatto, L. R. (1970). Surface integrity of machined structural components. Air Force Materials Laboratory.

Krar, S. F., \& Gill, A. (2003). Exploring advanced manufacturing technologies. Industrial Press Inc.

Kumar, A., Kumar, V., \& Kumar, J. (2012). Prediction of surface roughness in wire electric discharge machining (WEDM) process based on response surface methodology. IACSIT International Journal of Engineering and Technology, 2(4), 708-719.

Li, Q., Kucukkoc, I., \& Zhang, D. Z. (2017). Production planning in additive manufacturing and 3D printing. Computers \& Operations Research, 83, 157-172. doi:10.1016/j.cor.2017.01.013

Lutjering, G., \& Williams, J. C. (2007). Titanium. Springer-Verlag.

Majumder, A. (2012). Study of the effect of machining parameters on material removal rate and electrode wear during Electric Discharge Machining of mild steel. Journal of Engineering Science and Technology Review, 5(1), 14-18. doi:10.25103/jestr.051.03

Mellor, S., Hao, L., \& Zhang, D. (2014). Additive manufacturing: A framework for implementation. International Journal of Production Economics, 149, 194-201. doi:10.1016/j.ijpe.2013.07.008

Patel, A. M., \& Achwal, V. (2013). Optimization of parameters for Wedm machine for productivity improvement. Journal of Mechanical and Civil Engineering, 9(5), 10-14. doi:10.9790/1684-0951014

Polishetty, A., Shunmugavel, M., Goldberg, M., Littlefair, G., \& Singh, R. K. (2017). Cutting force and surface finish analysis of machining additive manufactured titanium alloy Ti-6Al-4V. Procedia Manufacturing, 7, 284-289. 10.1016/j.promfg.2016.12.071

Shamsaei, N., Yadollahi, A., Bian, L., \& Thompson, S. M. (2015). An overview of Direct Laser Deposition for additive manufacturing; Part II: Mechanical behavior, process parameter optimization and control. Additive Manufacturing, 8, 12-35. 10.1016/j.addma.2015.07.002

Shunmugavel, M., Polishetty, A., \& Littlefair, G. (2015). Microstructure and Mechanical Properties of Wrought and Additive Manufactured Ti-6Al-4V Cylindrical Bars. Procedia Technology, 20, 231-236. 10.1016/j. protcy.2015.07.037

Shunmugavel, M., Polishetty, A., \& Littlefair, G. (2017). Machinability studies of selective laser melted titanium alloy Ti-6Al-4V. Deakin University. 
Singh, H., \& Singh, E. (2013). Effect of Pulse on/Pulse Off on Machining of Steel Using Cryogenic Treated Copper Electrode.

Subrahmanyam, S., \& Sarcar, M. (2013). Evaluation of optimal parameters for machining with wire cut EDM using Grey-Taguchi method. International Journal of Scientific and Research Publications, 3(3), 1-9.

Suryakant, T., \& Allurkar, B. (2016). Literature Review on Electric Discharge Machining. International Journal of Scientific Engineering and Technology Research, 5(2), 404-406.

Ashwin Polishetty is a Senior Research Fellow at Faculty of Creative Technologies, AUT University. Polishetty has been actively involved in research on machinability of newly emerging, design-centric materials for aerospace, biomedical and automotive industry. Polishetty is a lead researcher of the machining and machinability group, advance manufacturing and related high-end technologies group. Research on additive manufacturing for aerospace and bio-medical industry has been a primary point of focus. Polishetty is a reviewer for reputed journals; keynote speaker, technical and organizing committee member, session chair and article reviewer for some international conferences

Guy Littlefair is the Pro Vice Chancellor and Dean of the Faculty of Design and Creative Technologies at Auckland University of Technology. Prior to his return to AUT in 2017, Professor Littlefair was the Pro Vice-Chancellor for Industry and Strategic Partnerships and earlier, the Dean of Engineering in the Faculty of Science, Engineering and the Built Environment at Deakin University in Australia. Combined with an academic career spanning 25 years, Professor Littlefair has also had the opportunity to spend time in industry. He has been a reviewer for reputed journals; keynote speaker, technical and organizing committee member, session chair and article reviewer for some international conferences. 